\title{
OP ZOEK NAAR DE INDIANEN
}

Het komt dikwijls voor, dat van achteraf gelegen gebieden meer studie is gemaakt dan van hetgeen meer voor de hand ligt. Het bijzondere trekt, het dagelijks waargenomene komt pas later binnen de sfeer van onderzoek.

Suriname als geheel mag in vroeger eeuwen het bijzondere zijn geweest en aanleiding hebben gegeven tot algemene beschrijvingen, de laatste honderd jaar is er aan de Indianen in het verre binnenland relatief veel aandacht besteed. Expedities ter afbakening van de grenzen en voor natuurwetenschappelijk onderzoek hebben hiertoe bijgedragen. En naarmate de Indianenstammen schaarser leken te worden, is de kennisneming van hetgeen binnen afzienbare tijd niet meer zou bestaan urgenter geacht.

Dit was mede een reden waarom pater AHLBRINCK, welbekend als auteur van de Encyclopaedie der Karaiben, in staat werd gesteld in 1937/38 een kleine expeditie te leiden naar Suriname 's zuidoosthoek, toen de grensexpeditie onder admiraal KÄYSER kort tevoren in aanraking was gekomen met enkele Indianen van een tot dan toe niet ontmoete stam.

Door de oorlog en allerlei omstandigheden daarna is het verslag van deze - zuiver wetenschappelijke - expeditie eerst nu uitgegeven ${ }^{1}$ ), en wel mede dank zij de steun van het Prins Bernhard Fonds dat pater AHLBRINCK in 1955 met de Zilveren Anjer onderscheidde voor zijn ,,grote wetenschappelijke prestaties op taalkundig en ethnologisch gebied betreffende de Karaïbische Indianen in Suriname". Op zoek naar de Indianen - het ging om de Wama's en de Wajarikoele's - kwam pater AHLBRINCK eerst in contact met de Wajana's, die verder ook als gidsen dienden. Het reisverhaal is in drie delen gesplitst, waarin elk der drie onderling vijandige stammen worden behandeld op grond van de ontmoetingen of .... van de verhalen over hen. Want de schrijver vindt van de Wama's maar enkele personen en de Wajarikoele's - zo luidt zijn conclusie moeten wel zijn uitgestorven met de dood van MALAwnI, de laatste vrouw van de stam, die bij de evangelist in Cottica een toevlucht had gevonden. Het bericht van haar overlijden bereikte pater AHLbrinck tijdens de expeditie, maar hij had Malawn te voren in Paramaribo kunnen interviewen en zij had een deel van de tocht meegemaakt.

De gegevens van vroegere reisverslagen worden vergeleken met de eigen vondsten en pater AHLBRINCK verklaart mede waarom het contact met deze Indianen zo moeilijk tot stand te brengen is geweest: de Bonninegers, de Bosnegers die zich in datzelfde gebied van de bronrivieren van de Lawa hadden gevestigd, hebben de directe aanraking tussen de bovenlandse Indianen en de benedenlanders zoveel mogelijk verhinderd om profijt te trekken van de ,,bemiddeling".

1) Op zoek naar de Indianen. Verslag van een expeditie naar de Zuidgrens van Suriname ter opsporing en bestudering van twee onbekende Indianenstammen: de Wama's en de Wajarikoele's, door W. AнLвrinck C.s.s.R. Mededelingen van het Koninklijk Instituut voor de Tropen, $\mathrm{nr}$ cxvin, afdeling Culturele en Physische Anthropologie nr. 56, 1956, 184 blz., foto's, kaarten. 
Het zijn dus schaarse, maar daarom des te waardevollere gegevens die verzameld zijn kunnen worden. En de spannende beschrijving van het zoeken zelf, de sporen, de aanwijzingen, de verrassingen, zal voor latere onderzoekers ook van algemeen nut kunnen zijn.

Een gedeelte van de tijd werd bij de Wajana's doorgebracht en zo kon pater AHLBRINCK zelf nog eens de bekende wespenproef bijwonen, die hij in alle details van deze wrede initiatie- en hardingsrite weergeeft, tevens een der oorzaken van de teruggang in getalsterkte dezer Indianen. Andere

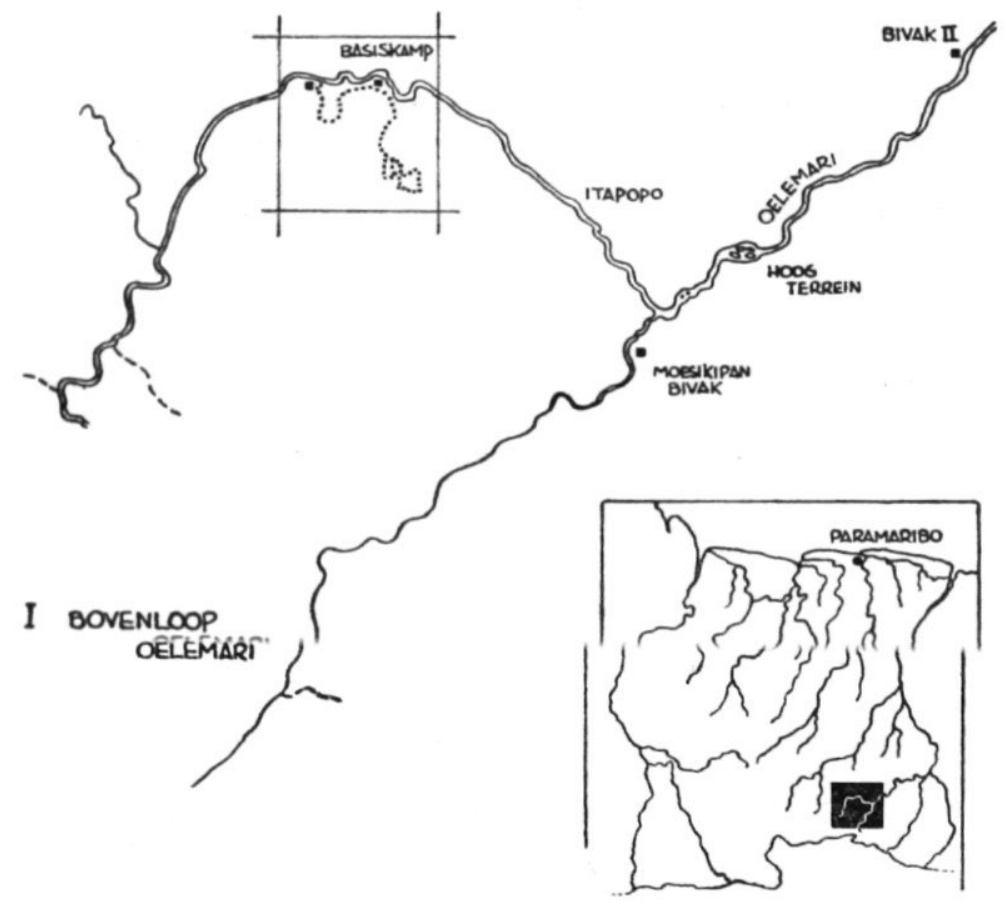

ethnografische gegevens vinden wij in het verslag, met foto's en tekeningen geïllustreerd, ten dele in aanvulling op de Encyclopaedie der Karaïben.

Wat pater AHLBRINCK over de Indiaanse gifpijlen vertelt is o.a. aanleiding geweest voor de Surinaamse gouvernementsbioloog, dr. GEIJSKES, om bij een latere tocht naar dit gebied de voor het vergif gebruikte planten te zoeken'1). Ook „Baas” LoDEwijk Schmidt, die vrijwel alle expedities naar de bovenlandse Indianen sinds \pm 1935 heeft vergezeld, maakte zelf na de tocht van pater AHLBRINCK nog een drietal reizen naar de grensstreek, waarvan een verslag is gepubliceerd dat ook in zekere mate aansluit op het onderhavige ${ }^{2}$.

1) D. C. Geijskes, Met de Oajana's op stap. Paramaribo, 1942.

2) LoDEWIJK Schmidt, Drie reizen naar de bovenlandse Indianen. Bewerkt door Gerold Stahel, Paramaribo, 1943. 
In 1953 ging de toenmalige districtscommissaris van Suriname, J. MicheLS $^{1}$ ), nogmaals naar de zuidoosthoek in gezelschap van de geologen Chr. Bleys en dr. V. C. DE MUNCK, het Statenlid Findlay en een militaire patrouille onder leiding van Kapitein SLEевоом ter beveiliging.

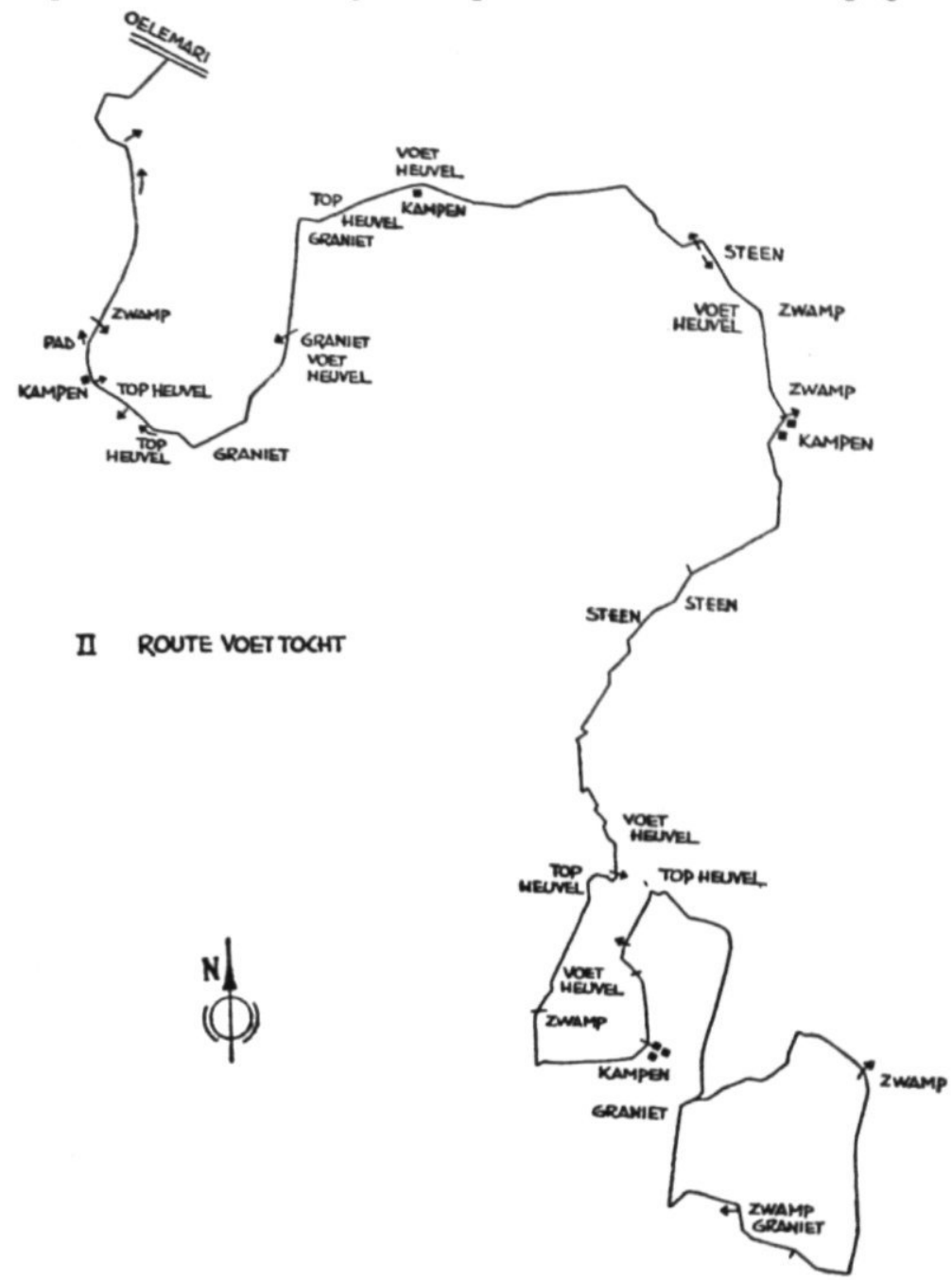

De verkenningen van deze expeditie brachten hen in dezelfde streek waar pater AHLBRINCK was geweest en het is op zijn verzoek, dat de heer MrcheLs in aanvulling op het hier besproken reisverslag de volgende gegevens ter beschikking stelde.

1) Thans hoofd van de afdeling Binnenlands Bestuur van het Departement van Binnenlandse Zaken.

Dr. DE MUNCK is eind 1956 bij een vliegtuigongeluk omgekomen. 
„Kaart I is een ruwe schets van de loop van de bronkreken van de Oelemari, met aanduiding van een voettocht die wij in maart 1953 vanuit de Noorder bronkreek maakten op enkele bospaden van onbekende Indianen, welke AhLBRinck Wama's noemt, maar die door de ons vergezellende Wajana's Wajarikoele's genoemd werden. Kaart II geeft de bijzonderheden van deze voettocht, met aanduiding van de plaatsen waar wij Wamaof Wajarikoele-kampen aantroffen. De foto geeft een afbeelding van één dezer kampen. Gelopen werd langs en op de sporen (gebroken twijgjes) dezer Indianen. De meeste kampen waren naar schatting gemaakt in de vorige droge tijd, d.w.z. ze waren ongeveer een half jaar oud. De bewoners troffen we niet. Dat ze niet ver waren, zou kunnen worden geconcludeerd uit voetsporen die wij één keer aantroffen in de modder bij een kreekje, welke voetsporen volgens de Wajana-hoofdman Janemale één dag oud waren, mede gelet op het feit, dat het in die dagen vrijwel dag en nacht regende.

De kampen waren naar onze schatting geruime tijd niet meer gebruikt. We troffen er barbakot-stellages en stenen voor de vuren bij aan, voorts boegroemakka-pitten en beenderen van wild. Bij de kampen doorgaans aan de voet van een boom de plaats waar vuur werd gemaakt, voorts eens een ruwe houten steel met een gat erin, de plaats waar volgens onze Wajana's de stenen bijlpunt bevestigd wordt en een andere keer een merkwaardig in doosvorm gevouwen palmblad, volgens de Wajana's zo gevouwen om er uit te drinken. Deze Wajana's gaven blijk een en ander te kennen, ook het maken van vuur met wat ik wil noemen een vuurboor.

Onze metgezellen waren overigens in het geheel niet gerust op de afloop van deze tocht; de Djoeka's liepen des nachts zelfs vrijwillig wacht rondom onze bivakken, omdat zij vreesden voor nachtelijke overvallen van de Wama's of Wajarikoele's.

Een verdere verkenning onzerzijds van de Noordelijke bronkreek moest na enige tijd worden opgegeven, omdat de kreek vol met omgevallen bomen bleek te liggen. Tijdens die tocht vonden wij op een plaats een liaan gebonden over de breedte van de kreek. Ook in de benedenloop hebben wij kampen van de onbekende of weinig bekende medeburgers, de Wama's aangetroffen. In en nabij de Zuidelijke bronkreek, waar een deel onzer expeditie, onder leiding van de bekende Baas Schmidt opereerde, werden geen sporen van bewoners aangetroffen". Tot zover de heer Michels.

De puzzle van de Wama's en de Wajarikoele's is dus nog niet opgelost. De ervaringen van de heer Michels c.s. mogen de lezers een aansporing te meer zijn om aan de hand van pater AHLBRINCK op zoek naar Indianen te gaan.

Johanna Felhoen KraAl 